\title{
Aporia e Trauma na Crise de Significados do Onze de Setembro*
}

Erica Simone Almeida Resende**

\author{
There have been no words. \\ $i$ have not written one word. \\ no poetry in the ashes south of canal street. \\ no prose in the refrigerated trucks driving debris and \\ dna. not one word. \\ First writing since \\ Suheir Hammad
}

Em carta a um conterrâneo, o escritor inglês Peter Carey (2001), morador de Nova Iorque, descreve o mês de setembro de 2001: "A última semana foi um grande borrão, sem diferença entre o dia e a noite. O tempo está partido. Os eventos do primeiro dia sangraram

* Artigo recebido em novembro de 2009 e aprovado para publicação em maio de 2010.

** Doutora em Ciência Política pela Universidade de São Paulo (USP) e pesquisadora associada do Programa de Pós-Graduação em Relações Internacionais (PPGRI) da Universidade Estadual do Rio de Janeiro (UERJ). E-mail: esa@infolink.com.br.

CONTEXTO INTERNACIONAL Rio de Janeiro, vol. 32, n 1, janeiro/junho 2010, p. 205-238. 
para o seguinte e, agora, não consigo ordenar as fortes emoções e as visões perturbadoras em uma sequência adequada". 1 O trecho expressa o sentimento que tomou todos de assalto: "Estão com tal pesadelo marcado a ferro e fogo no tecido do córtex cerebral", escreveu. O que aconteceu naquele dia capaz de gerar tal representação? O que houve de tão especial, ou inédito? Mais do que a perda de vidas e os prejuízos financeiros, aquele dia gerou um sentimento generalizado de que o mundo havia mudado. O tempo havia-se partido e a data de 11 de setembro de 2001 passou a significar algo único: o Onze de Setembro.

Tradicionalmente, quando fazemos menção a um evento, pensamos em algo que tenha ocorrido fora da normalidade, do fluxo da própria História. Os eventos do Onze de Setembro, com efeito, alteraram nossa percepção espaço-temporal. Nossa sensação, independente do local em que nos encontrávamos, fosse São Paulo, Pretória, Berlim, Sidney, Mumbai ou Tóquio, era de que Nova Iorque e Washington chegavam a nossas casas em tempo real, ao vivo e em cores, através das telas de televisores e de computadores. A virtualidade da experiência também contribuiu para o sentimento de que o tempo estava fora de compasso, deslocado. Justamente o tempo partido mencionado por Carey.

Rayner (2002) resumiu a sensação de como era impossível tocar adiante as tarefas do cotidiano naquele dia. A data foi marcante, não por causa das mortes, ou dos prejuízos, mas por ter "nos aberto para um outro tempo: de conflito, transformação e decisão". O Onze de Setembro, prossegue, assim como todo evento histórico, não nos confrontou: "ele nos engoliu, nos incorporou a seu próprio processo de desenvolvimento e assim nos transformou". O mundo pode até continuar a ser materialmente o mesmo, mas "nossas trajetórias existenciais, nossos padrões de existir" foram mudados, afirma ele.

Aos que foram capazes de reconhecer que "algo novo sob o sol" havia ocorrido (TALBOT; CHANDA, 2002, p. 10) e que por baixo da 
Aporia e Trauma na Crise de Significados do

retórica imediata para seguir em frente - bussiness-as-usual - teria ocorrido um deslocamento definitivo na visão do mundo, faltava agora compreender o que aconteceu na manhã daquele dia. Na dificuldade de responder a essa pergunta - "O que aconteceu?" -, reside o grande problema de datas como a do Onze de Setembro: a incapacidade de significação da realidade naquele momento, apesar do pleno reconhecimento de sua natureza de ruptura, ou de crise. Na verdade, um acontecimento que provoque tamanho choque, estupefação e perturbação a ponto de fazer os indivíduos perderem a capacidade de articular, processar, registrar e entender algo é um evento que escapa a toda e qualquer significação. Conforme bem observaram Passavant e Dean (2002), o Onze de Setembro constitui um evento fora da ordem da representação e da inteligibilidade.

Recorremos ao relato de Edkins (2002, p. 243) para vislumbrar o problema da significação da realidade em um momento de crise como o de 2001:

Uma das imagens mais marcantes do Onze de Setembro foi a das pessoas nas calçadas de Nova Iorque, com as mãos à boca, petrificadas e horrorizadas enquanto assistiam ao impossível virar real perante seus olhos. O gesto era repetido, continuamente, em nossos televisores, juntamente com a repetição dos aviões colidindo contra os prédios, sendo testemunha do que não podia ser dito. Não se ouviam gritos. Somente o horror silencioso. [...] Os jornais do dia seguinte traziam somente fotografias. E na cobertura televisiva, repetidamente, não havia narração, somente uma imagem subjacente às histórias e debates, como se quisesse mostrar, repetidamente, para quem ainda não tivesse visto, que aquilo era real. As pessoas estavam sentadas em silêncio, amortecidas, pensando, porém incapazes de pensar, atônitas. 
Outro relato que transmitiu a incapacidade de significação da realidade veio de uma jornalista que descrevia ao vivo a movimentação no aeroporto da cidade: "Ninguém está falando nada. Só olham uns para os outros com os braços abaixados ao longo do corpo. Dá para ouvir um alfinete cair no chão. Ninguém fala nada. [...] Centenas de pessoas amontoadas sem saber o que fazer e ninguém fala absolutamente nada". 2

A dificuldade de significação existiu, apesar da invasão de imagens em tempo real, entrando em todos os lares ao redor do mundo por televisores, pela internet e por antenas parabólicas. O Onze de Setembro foi experimentado pessoal, visual, digital, virtual, global e simultaneamente como nenhum outro evento da História. A sensação dominante foi a de que as imagens não podiam ser reais; elas só poderiam pertencer a filmes de catástrofe produzidos em Hollywood. Campbell (2001) comenta como a enorme quantidade de imagens reforçava a mudez (speechlessness) do evento:

Esses eventos reais, em tempo real, nos alcançavam pela realidade da televisão. Em loop contínuo, o vídeo daqueles extraordinários 100 minutos que registraram a morte de 6 mil pessoas era repetido, reutilizado e reciclado a perder de vista, marcando aquelas imagens na mente coletiva. E, mesmo assim, aquelas imagens teimavam em desafiar a compreensão.

Mais do que nunca, era impossível não lembrar das palavras de Susan Sontag (1990, p. 17) sobre o privilégio da fotografia como meio de representação: "Cada foto é um momento privilegiado transformado em um fino objeto que pode ser guardado e revisto". 3 Diversos foram os momentos e instantes capturados em imagens que pareciam se colar diretamente em nossas retinas. Nesse sentido, a imagem do momento da queda de um homem de uma das torres (Figura 1) representa não apenas o horror da tragédia da perda de uma vida, mas a força 
Aporia e Trauma na Crise de Significados do Onze de Setembro

\section{Figura 1}

"The Falling Man"

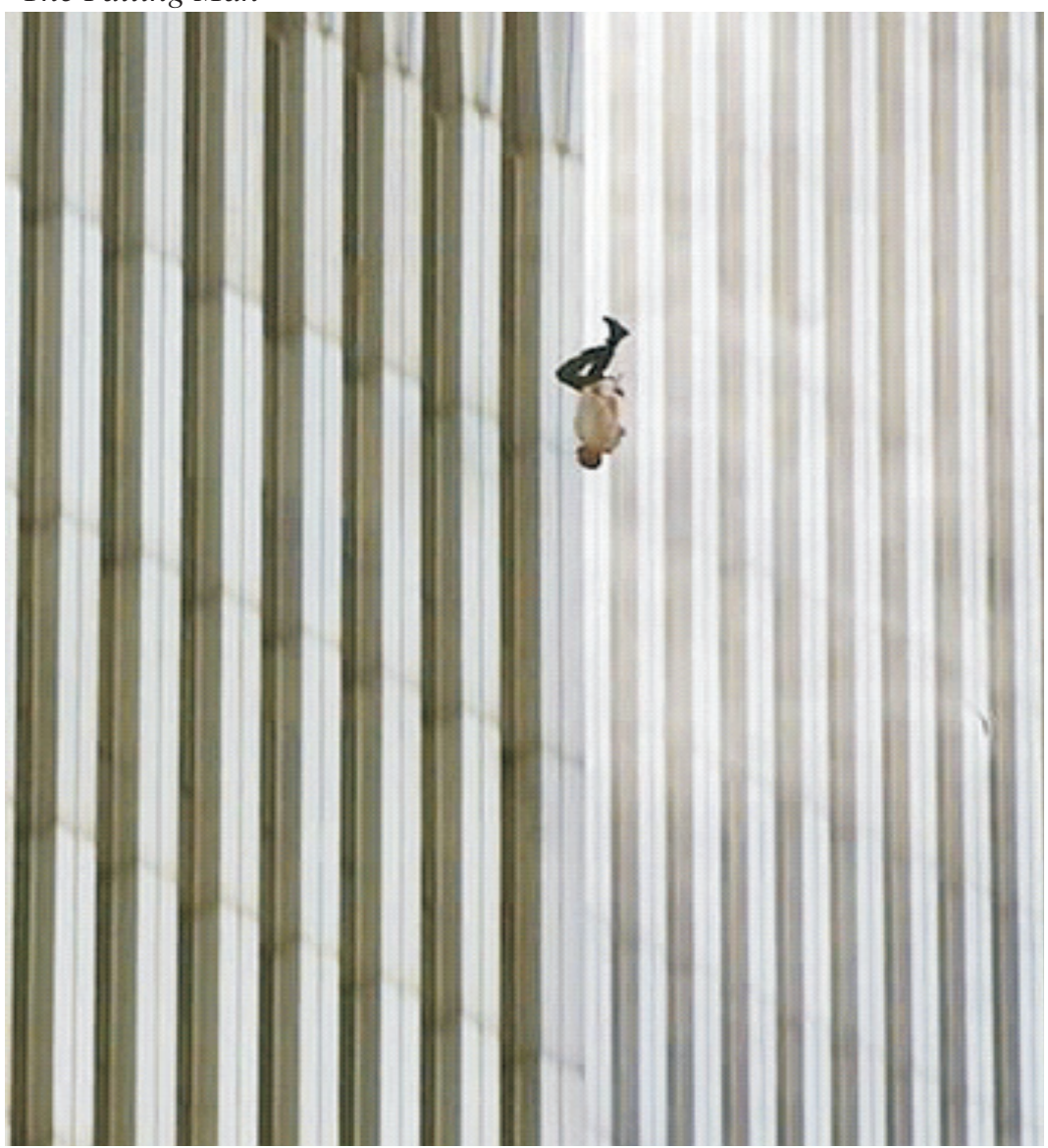

Fonte: WorldPress.com. Disponivel em: <http://911allthetruth.wordpress.com/2008/11/08/hombre-aire-falling-man/>. Acesso em: 13 abr. 2009.

do silêncio que a imagem congelada de um fragmento de um instante de horror nos impõe a ver e reviver de forma incessante e sufocante.

Com efeito, a fotografia de Richard Drew evoca a mesma ligação entre queda e trauma que Eleanor Kaufman (1999) já havia postulado. Segundo ela, a palavra "queda" funciona como marcador da qualida- 
de abismal da lógica do trauma. É significante da perda do controle e do equilíbrio, da queda no abismo, do nada sob os pés. Não vemos nem seu início nem seu fim; somente a queda infinita no abismo. De certa forma, a imagem traduz o sentimento do próprio evento do Onze de Setembro: não vemos seu início, causa ou origem, muito menos vislumbramos seu término. Há somente a certeza de que estamos caindo, com destaque para o gerúndio. A imagem anterior define as fronteiras do suportável à mente humana, submetendo-nos a uma identificação mimética com a morte que é intolerável.

Naquele dia, e nos que se seguiram, milhares de imagens pareciam nos sufocar, seguindo-nos aonde quer que fôssemos. Centenas de pessoas testemunhavam, atônitas, mais do que a queda das torres: viam o impensável tornar-se real diante do mesmo horror mudo e imobilizante que Munch soube capturar (Figura 2).

A angústia existencial de Munch fez-se sentir nas semanas seguintes, conforme a apropriação realizada pela iraniana Reza Sepahdari (Figura 3), ao tentar capturar o sentimento de choque quanto a algo que não conseguia ser entendido, processado ou racionalizado pelas formas tradicionais de significação. Lembrando Primo Levi (1987, p. 96), foi o momento em que o horror foi "violenta e irrevogavelmente introduzido no mundo das coisas reais".

A escritora Caroline Knapp (2001) tentou verbalizar sua perplexidade:

Medo e terror, os sentimentos que dominaram o início da semana, cederam lugar a um desânimo vago e pesado. As histórias de tragédias pessoais começavam, cruelmente, a se misturar. Até mesmo a linguagem falhava, fazendo com que a maioria das pessoas que conheço recorresse a uma única palavra vazia: "atônito". "Estou atônito". "Não sei o que fazer". "Simplesmente atônito", repetiam à minha volta. 
Aporia e Trauma na Crise de Significados do Onze de Setembro

\section{Figura 2}

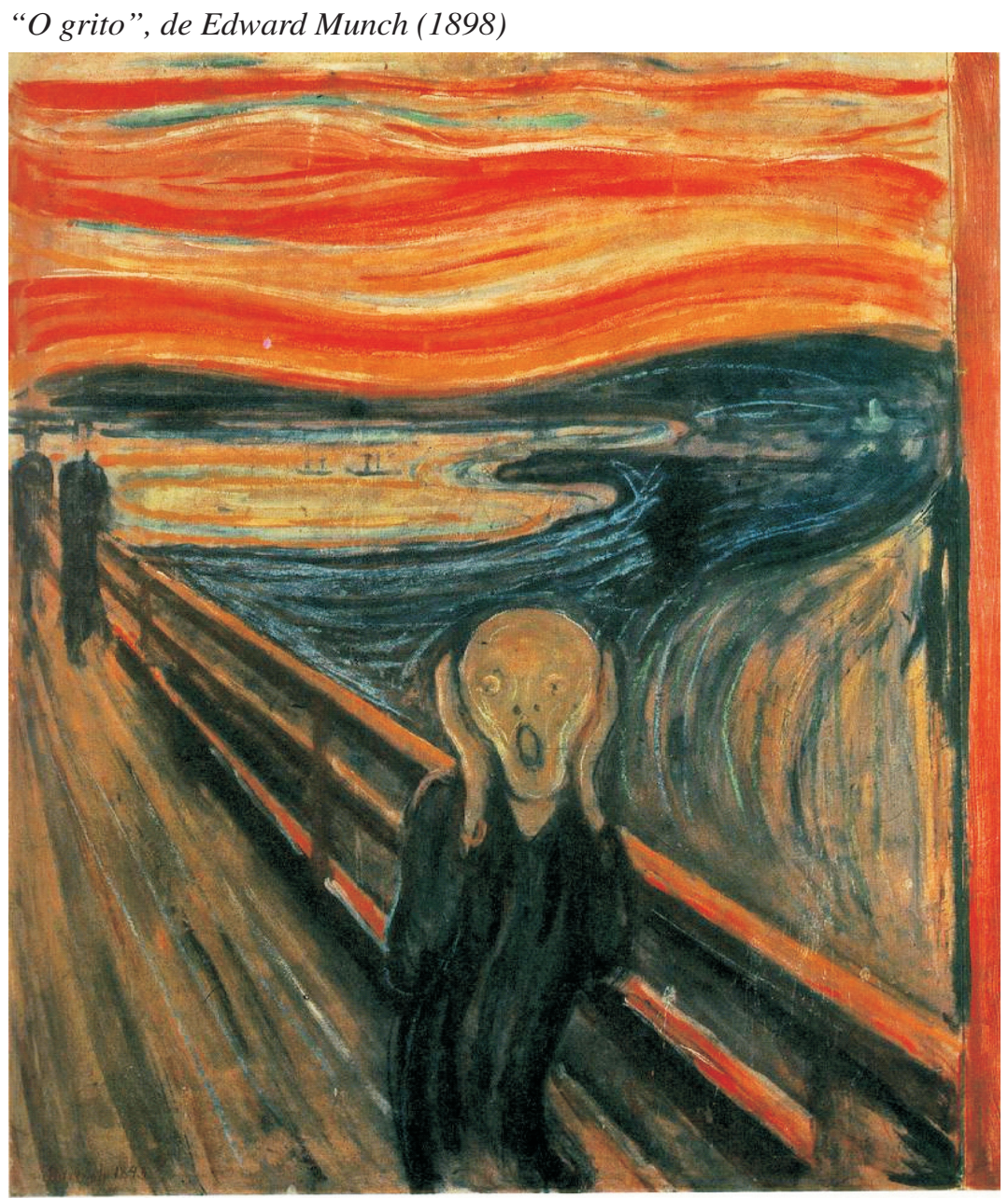

Fonte: Ibiblio. Disponível em: <http://www.ibiblio.org/wm/paint/auth/munch/>. Acesso em: 13 abr. 2009.

Eis o grande problema do Onze de Setembro: a dificuldade de significação de uma experiência além dos limites da linguagem e da inteligibilidade humana.

Conforme observou Campbell (2001), em cada esquina de Nova Iorque, havia um fotógrafo, ou uma equipe de TV, procurando um novo 


\section{Erica Simone Almeida Resende}

\section{Figura 3}

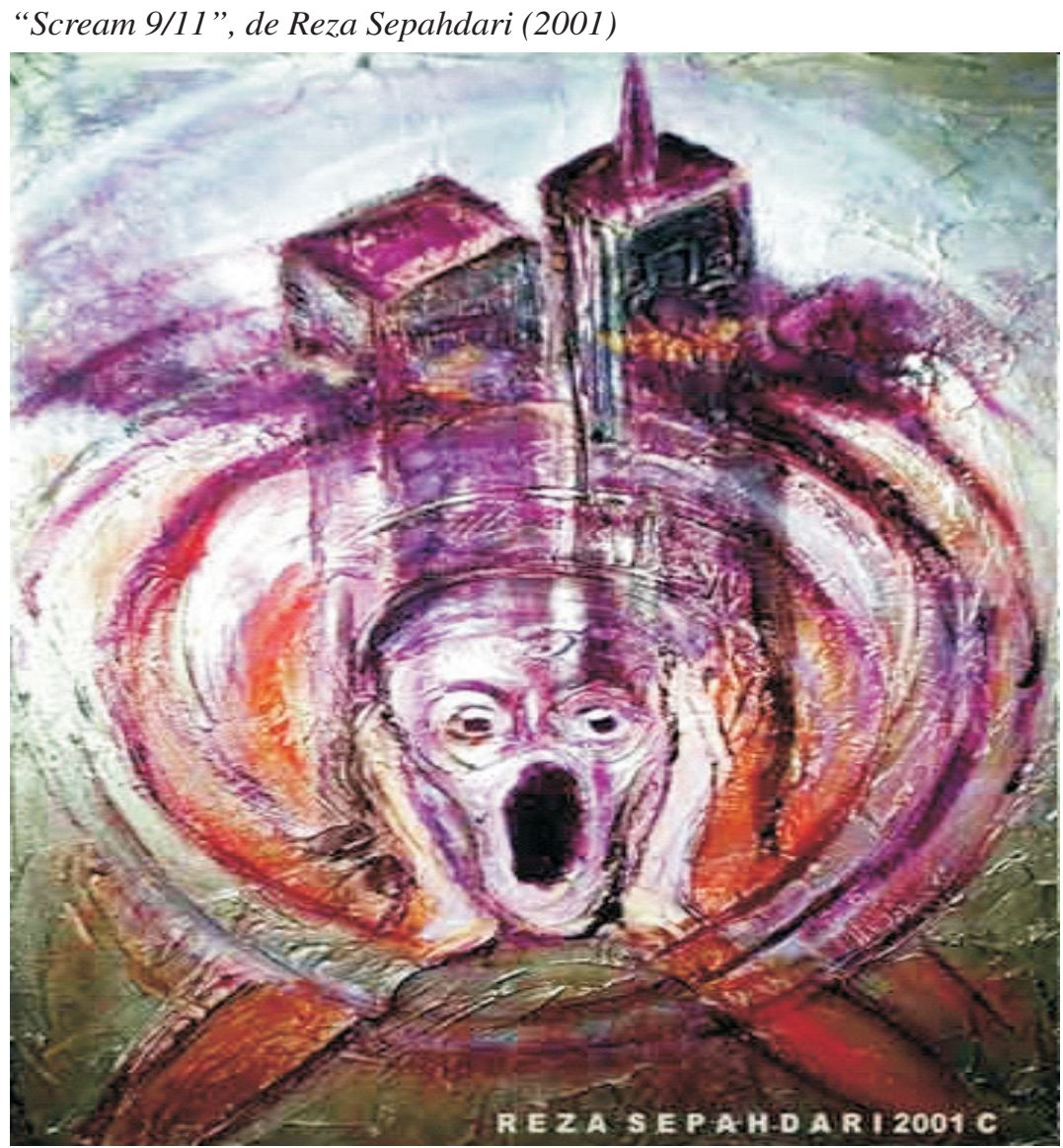

Fonte: Disponivel em: <http://br.wrs.yahoo.com/_ylt=A0WTf2x6t.NJvt4Ar2z.6Qt./SIG= 12qc167a7/EXP=1239746810/*kttp\%3A//www.vcn.bc.ca/waca/Sep\%252011Art\%2520Show/911Ex hibition-14.html>. Acesso em: 13 abr. 2009.

ângulo, todos buscando desesperadamente compreender o que havia ocorrido. Essa "busca por entendimento" era central para reconhecer a qualidade de evento (event-ness) do Onze de Setembro. Citando Allan Feldman, Campbell (2001) observa que o evento não é aquilo que acontece per se, mas o que pode ser narrado. E a clara dificuldade em narrar o Onze de Setembro sinalizava o grau de ruptura de significados experimentado pela coletividade. 
Aporia e Trauma na Crise de Significados do

De fato, a exposição a um evento tão inesperado e impensável, capaz de gerar tamanha desorientação, fez com que os indivíduos - e aqui destacamos que não estamos, necessariamente, referindo-nos apenas aos moradores das áreas atacadas, mas a todos que experimentaram o evento em tempo real, inclusive virtualmente - perdessem toda e qualquer certeza quanto à realidade e a si próprios. Essa incapacidade de processar, absorver e compreender o ocorrido em decorrência do deslocamento abrupto de significados e de representações da realidade nos leva a caracterizar o Onze de Setembro como um momento de aporia, de perda de significados, aprofundada por dois elementos que, em conjunto, deram um caráter peculiar ao Onze de Setembro.

Primeiro, o fato de os ataques terem sido transmitidos ao vivo por um número incalculável de emissoras de TV, rádio, canais de notícias 24 horas, tanto de sinal aberto quanto fechado, gravações de amadores, registros em aparelhos celulares, em websites, blogs etc. Um espetáculo $^{4}$ de imagens, como aponta uma pequena amostra de capas de jornais e revistas expostas nas bancas do mundo no dia seguinte (Figura 4). Quase despidas de texto, elas principalmente mostram imagens.

A exposição prolongada e exagerada a essa avalanche de fotogramas, multiplicada por vídeos em loop contínuo, 24 horas por dia, durante semanas e meses, não apenas reforçava a aporia, como também impedia, nas palavras de Der Derian (2002b), um ponto de observação e de reflexão distanciada. Retomando o relato de Knapp (2001), podemos perceber a "ausência de significado" diagnosticada por Campbell (2002) e a dificuldade de lidar com as emoções que a aporia produziu:

Não estou acostumada a experimentar uma gama tão ampla de tipos conflitantes de sentimentos ao mesmo tempo. Normalmente, é um sentimento de cada vez, talvez dois. Ansiedade 


\section{Erica Simone Almeida Resende}

\section{Figura 4}

Capas de Jornais e Revistas Dedicadas ao Onze de Setembro
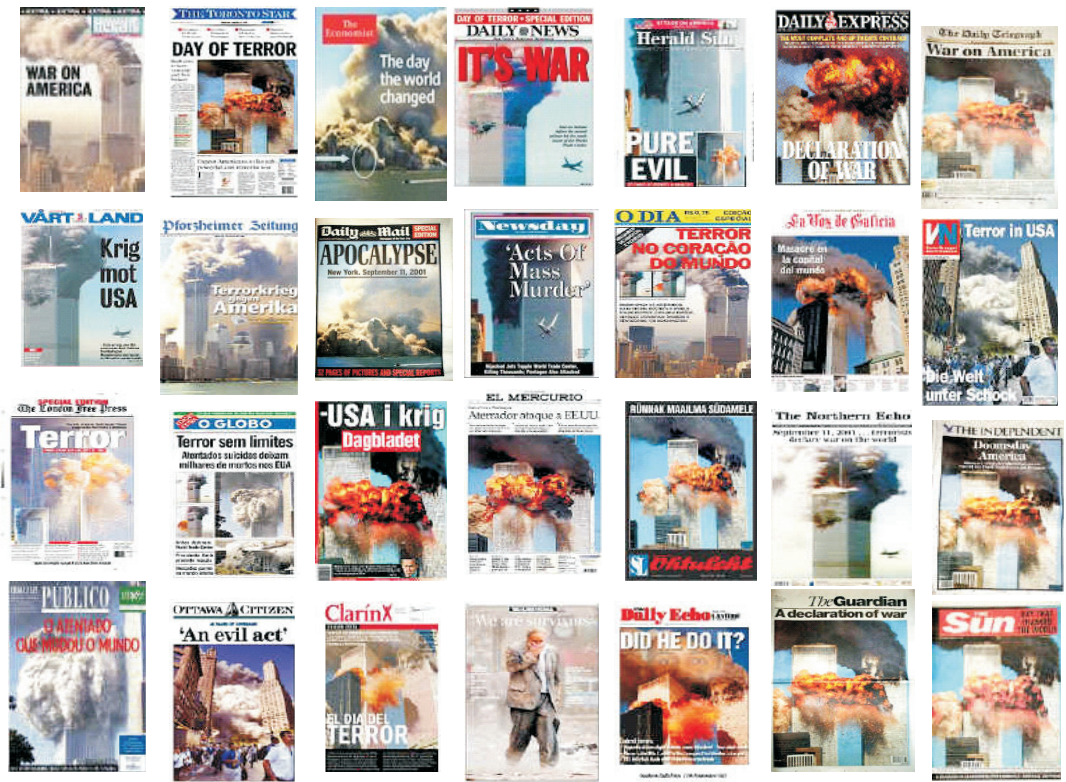

Fonte: September 11 News.com. Disponível em: <http://www.september11news.com>. Acesso em: 13 abr. 2009.

aqui; contentamento ali. Uma pitada de melancolia num dia ruim; um clarão de alegria num dia bom. Mas na sexta-feira, e entrando semana adentro, esse simples sistema sináptico estava totalmente fora dos eixos, com a consciência sobrecarregada. Isso pode ser normal, mas é extremamente desorientador. A magnitude da devastação física, o medo do que estava por vir, a sensação de inesperada vulnerabilidade, o alcance da dor, cada vida perdida que tocava fundo um número incalculável de outras vidas: isso é mais do que um cérebro normal pode processar, fazendo com que a mente pule de uma sensação a outra. Era impossível parar em apenas uma ou absorvê-las todas de uma vez. 
Aporia e Trauma na Crise de Significados do

Ao recordar o relato autobiográfico do correspondente de guerra Michael Herr (1991), Der Derian (2002a) faz uma analogia entre o Vietnã e o Onze de Setembro, no que toca à produção e ao consumo de imagens. Na sua opinião, ainda, os acontecimentos de 2001 teriam sido, sobretudo, uma guerra de redes:

Desde o início, ficou claro que o Onze de Setembro era e continuaria a ser uma guerra de redes. Rede terrorista, da internet ou do horário nobre, as redes estavam ligadas no "empurra-e-puxa" da disseminação de violência, medo e desinformação. Por um longo tempo, na primeira semana de confusão e caos em que não havia distanciamento, elas pareciam quase neutras, afogando os espectadores num ciclo de 24 horas de imagens trágicas de destruição e morte. [...] Parecia que a cultura política norte-americana experimentava um trauma coletivo freudiano que podia ser revivido (eternamente na TV a cabo e na internet), mas não compreendido no momento do choque. Era isso que Michael Herr queria dizer quando escreveu sobre sua experiência com o trauma do Vietnã: "Foi a guerra que me ensinou que somos responsáveis por tudo que vemos, assim como por tudo que fazemos. O problema é que nem sempre você entende o que está vendo até bem mais tarde, talvez anos depois, e muito daquilo você ainda fica sem entender, e fica para sempre alojado nas retinas" (DER DERIAN, 2002a, p. 181-182).

Por tais razões, o papel das redes de mídia no aprofundamento da aporia não deve ser subvalorizado. $\mathrm{O}$ fato torna-se bastante relevante considerando que, nos Estados Unidos, ao contrário do que ocorre em outros países, parece ser a mídia, em vez da família, da comunidade local, da sociedade civil ou do governo, em razão de sua velocidade, recursos e penetração, a que primeiro oferece uma resposta ao 
momento de crise. Der Derian (2002a, p. 182) finaliza: "perguntas sobre utilidade, responsabilidade e culpa surgiram inevitavelmente e, como era de se esperar, o menu de opções da mídia não estava preparado para o colapso gêmeo da invulnerabilidade dos Estados Unidos".

O segundo elemento que aprofundou a aporia é identificado por Göle (2002) ao comentar como os episódios foram especialmente "sem voz". Reconhecendo que a História deve ser interpretada tanto por imagens quanto por narrativas, ele argumenta que a dificuldade de encontrar palavras apropriadas para compor uma narrativa era devida, em parte, à forma não usual dos atos terroristas. Para Göle (2002), a mudez foi acentuada porque não houve reivindicação de autoria, fosse para chamar atenção para uma causa, para fazer exigências, para responsabilizar governantes ou para se vangloriar. Esperamos e precisamos de um desfecho para as narrativas, e esse desfecho, no Onze de Setembro, nos havia sido violentamente negado. Para o analista político:

Normalmente, o terrorismo não tem rosto; mas agora também não tinha voz. Assim como Nova Iorque, estava mutilado e mudo. O silêncio acompanhou a catástrofe. Ausência de reivindicações por parte dos criminosos; ausência de narrativas por parte dos espectadores. Fomos reduzidos a espectadores passivos; era como assistir a um filme mudo sobre o apocalipse. [...] O terrorismo invadiu o palco da História, mas seus espectadores foram reduzidos ao silêncio e à impotência, tendo sua capacidade de agir e intervir bloqueada, e sua vontade subjetiva para agir aniquilada (GÖLE, 2002, p. 334).

Reconhecida a ruptura, era hora de tentar superar a crise e domesticar o evento, concedendo-lhe representação e significado, enquadrando-o em uma narrativa coerente de forma a restabelecer a ordem. Sur- 
Aporia e Trauma na Crise de Significados do

gia uma demanda coletiva para dar sentido ao Onze de Setembro. Fazia-se necessário significá-lo em alguma sequência ordenada de causa e efeito capaz de suturar a disjunção espaço-temporal-linguística provocada por aquele dia.

$\mathrm{Na}$ absoluta incapacidade de gerar uma análise distanciada, as primeiras tentativas de significação recorreram a antigas estratégias de diferenciação e de equivalência com base em significados e representações já conhecidos. Nesse sentido, o uso de expedientes como metáforas, analogias e metonímias tendeu a privilegiar a negação, a História e os horrores não específicos. Expressões como "É coisa de filme!", "Parece Pearl Harbor" e "É o fim do mundo" exemplificam as primeiras tentativas de significar os eventos.

Logo nos primeiros dias, parecia claro que qualquer narrativa capaz de dar sentido ao Onze de Setembro deveria, em maior ou menor grau, reconhecer-lhe um caráter de data histórica, de evento único e singular. Surgiu de imediato um "antes" e um "depois" de 11 de setembro, assim como o "antes" e o "depois" da destruição da Bastilha, em 14 de julho de 1789; o "antes" e o "depois" do assassinato de Francisco Ferdinando, em 28 de setembro de 1914; o "antes" e o "depois" da queda do Muro de Berlim, em 9 de novembro de 1989. ${ }^{5} \mathrm{O}$ ano de 2001 rapidamente se juntou a 1929, 1945, 1973 e 1989 para sinalizar mais um "ponto de virada" (turning point): o 11 de setembro de 2001 cedia lugar ao Onze de Setembro.

Desafiando a narrativa de excepcionalidade, Der Derian (2002b) lembrou os relatos do atentado terrorista ao World Trade Center de 1993, que, ao seu ver, eram semelhantes aos de 2001. Segundo ele, a data recebeu o rótulo de "a-historicidade excepcional" (DER DERIAN, 2002c, p. 178), um momento que não podia ser explicado dentro do curso normal da História, se considerada em relação à então tese do "fím da História". 6 
Sobre essa narrativa de data-marco e sobre suas implicações para a produção de conhecimento, Der Derian (2002c, p. 177) observa o seguinte:

\begin{abstract}
Antes de 11/9 e depois de 11/9: todos os cientistas sociais devem agora analisar a política internacional e a política doméstica com base nesse marco temporal. No entanto, por diversas razões, muitos parecem presos a um ínterim prolongado que impede a investigação acadêmica. Obviamente, por seu mero alcance, dimensão e choque, o próprio evento é parcialmente culpado por isso. Talvez seja bom repetir o que era ouvido nas conferências acadêmicas depois da queda do muro de Berlim: os cientistas sociais não deveriam posicionar causa e efeito com base em um único ponto de informação.
\end{abstract}

Der Derian (2002b) alerta-nos para caracterizações imediatas e simplistas, especialmente narrativas de uma data excepcional para a qual nenhuma teoria se prestaria mais. Seu objetivo em relembrar os relatos do primeiro ataque terrorista de oito anos antes é pedir cautela na "interpretação do terrorismo sob os holofotes - muitas vezes cegantes - dos eventos de Onze de Setembro", de forma a evitar lê-los "como exceção que impede o pensamento crítico e justifique um estado de emergência permanente" (DER DERIAN, 2002b).

De qualquer maneira, para retirar da data de 11 de setembro de 2001 sua áurea de "excepcionalidade a-histórica", urge promover algum tipo de intervenção crítica para desconstruir o discurso que lhe confere excepcionalidade. Rayner (2002) recomenda primeiro "viver o tempo do evento", ou seja, domesticá-lo para que possamos nos responsabilizar por suas consequências. Tal postura implica colocar o acontecido em seu devido contexto histórico. "Viver o tempo do evento" implica articular uma narrativa capaz de nos fazer entender o que aconteceu sem cair na velha armadilha de emitir julgamentos de 
valor e de alocar culpas. Temos que buscar uma narrativa de neutralidade capaz de evitar conflito.

O problema, entretanto, é que os episódios pareciam validar a tese do "choque de civilizações", fortalecendo uma narrativa que simultaneamente explicava o evento, apontava culpados e propunha uma política para impedir um novo Onze de Setembro. De acordo com Huntington (1996), o cenário internacional do pós-Guerra Fria passaria a ser marcado não mais pela rivalidade entre dois sistemas político-ideológicos rivais, mas pelo confronto entre civilizações excludentes. A tese oferecia aos norte-americanos uma representação de mundo de lógica simples e confortável, bastante análoga à dos tempos da Guerra Fria. No entanto, ao invés da União Soviética, agora surgia a "civilização islâmica". A bipolaridade ideológica LesteOeste seria substituída pela bipolaridade religiosa Ocidente-Oriente.

Todavia, houve "uma fratura que tomou de assalto o comando da memória", nas palavras de Göle (2002, p. 333), e construir uma narrativa coerente para compreender o porquê dessa fratura era urgente. A tese de Huntington, embora simplista e passível de crítica, foi capaz de atender aos anseios imediatos por uma explicação para os eventos do Onze de Setembro. A tese não só apontava os culpados (terroristas mulçumanos) e explicava as motivações (civilização/cultura/religião contrária à modernidade e ao Ocidente), como também formulava uma proposta de ação para evitar novos ataques (por ser um conflito entre civilizações excludentes, o confronto era a única saída).

Para a linguista Linde (1993, p. 114), narrativas unem pessoas: "Contar histórias cria sentimento de pertencimento ao grupo e solidariedade entre seus membros". Em tempos de incerteza e de ansiedade, elas funcionam como canais de interpretação da realidade ao tentar domesticar e disciplinar a estranheza e a inteligibilidade. Em outras palavras, elas tentam reconstituir o sistema de significados e de repre- 
sentações que dava sentido ao mundo, ajudando os indivíduos a superar a aporia aberta pela crise. $^{7}$

A posição é compartilhada por Ross (2002, p. 305), que sustenta que "as narrativas são especialmente relevantes para grupos e indivíduos presos em situações de grande incerteza e alto estresse". Quando os indivíduos se encontram desorientados, prossegue Ross, eles tentam dar sentido àquilo que experimentam sensorialmente. As narrativas coletivas reafirmadas dentro da coletividade ajudam-nos a encontrar consolo e a lidar com a ansiedade. Por essas razões, as narrativas "não saem de um mesmo saco": elas têm de estar ancoradas em experiências e em anseios interpretados seletivamente para que possam ter ressonância na coletividade. Concluímos, assim, que as narrativas, em especial as que tentam superar momentos de crise, possuem raízes na cultura daquela coletividade específica.

O conceito de cultura por nós empregado possui origem na semiologia, como proposto por Geertz (1973): ${ }^{8}$ sistema de "teias de significados", historicamente transmitido e identificável por meio de símbolos pelos quais os indivíduos "comunicam, perpetuam e desenvolvem saberes e atitudes sobre a vida". Ao enfatizar o caráter público da cultura, Geertz permite-nos entendê-la como sistema de representações transmissor das crenças cognitivas e afetivas que os membros de um grupo fazem sobre a realidade e sobre si. O compartilhamento dessas crenças faz com que eles se identifiquem, de forma mútua, em relação àqueles que não as compartilham. Trata-se de cultura como lente para interpretação da realidade capaz de, simultaneamente, expressar um "modo de vida" distinto e marcar o pertencimento. É, portanto, geradora de we-feeling, de Wir-Gefühl.

Em situações de crise e de ruptura, as narrativas evocam o passado imaginário da coletividade para ressignificar os sentidos contidos no "modo de vida" do grupo, adaptar e reconstituir as crenças cognitivas e as afetivas dos indivíduos sobre a realidade e sobre si mesmos. Di- 
Aporia e Trauma na Crise de Significados do

ante da ambiguidade, da incerteza e da ansiedade provocadas pela crise, as narrativas buscam reconectar as identidades individuais e as coletivas, ressignificando a realidade e o sentido das coisas para os indivíduos. Com efeito, a crise é o momento privilegiado para enfatizar o sentimento de solidariedade dentro do grupo, reforçar o imaginário coletivo de origem e destino comum, inibir o dissenso interno e disciplinar corpos e comportamentos.

Apesar das diversas consequências econômicas, políticas e militares que aquela manhã de setembro produziu, entendemos que a mais importante e, injustamente, subvalorizada teria sido a crise de significação produzida pelo Onze de Setembro. A ruptura do quadro de inteligibilidade que dava sentido ao mundo, expressa na dificuldade de exprimir linguisticamente o ocorrido e de articulá-lo em uma narrativa coerente, teria sido responsável por um trauma coletivo nacional.

A dificuldade em dar sentido à realidade e a si próprios, a partir de uma crise como a do Onze de Setembro, revela-se muito mais profunda do que uma mera dificuldade de compreender atos até então impensáveis e imprevisíveis. A proliferação quase que imediata de perguntas do tipo "O que aconteceu?", "Por que fizeram isso?" e talvez, a mais sintomática de todas - "Por que nos odeiam tanto?" sinalizava algo mais relevante e profundo acerca daquele momento: um trauma.

Torna-se necessário entender as implicações do trauma do Onze de Setembro no contexto específico da noção de segurança, sobretudo sua relação com os discursos de identidade nacional, de soberania e de poder estatal na sociedade norte-americana nos meses e anos que se seguiram a setembro de 2001. O que podemos dizer sobre o trauma? O que ele representa? Qual sua relação com o problema da segurança e, especificamente, com a comunidade política no marco do Estado nacional? 
Primeiro, porém, urge reconhecer e caracterizar o trauma. Nas palavras de Caruth (1996, p. 11), “o trauma descreve uma experiência devastadora com um evento inesperado ou catastrófico no qual a reação ocorre por meio de alucinações atrasadas, incontroláveis e repetitivas, e de outros fenômenos intrusivos". Trata-se daquilo que se encontra além da experiência, fora das fronteiras da linguagem, da compreensão normal, no "limite da escrita" (BLANCHOT, 1995, p. 7). O trauma expressa a incapacidade momentânea da linguagem em significar a realidade: a exposição a um evento tão perturbador e desestruturador que nosso sistema de referências sobre a realidade é abalado.

De acordo com Edkins (2002), o trauma implica um sentimento de traição em relação a nossas expectativas sobre a ordem das coisas. "Ele traz à tona questões existenciais que, pelo menos no mundo moderno, preferimos deixar submergidas", observa (EDKINS, 2002, p. 245). Por isso, o trauma implica reconhecer realidades e limites "que não estamos prontos para enfrentar” (EDKINS, 2002, p. 245). A mente humana não consegue processá-lo como faz com outros acontecimentos normais. Por se situar "fora da experiência comum", o trauma posiciona-se fora do arcabouço da realidade social normal e, por isso, fica além da linguagem e de outras ferramentas que tradicionalmente nos auxiliam a dar sentido ao mundo.

Esse é o paradoxo do trauma: é sentido, mas não compreendido; é memorizado e relembrado, mas não necessariamente vivido; é refratário à linguagem, mas exige ser comunicado; não admite ser incorporado à normalidade, mas insiste em se perpetuar na memória; é provocado em um ponto específico no tempo, mas altera sua linearidade; requer ser esquecido, mas é sempre relembrado e revivido. $\mathrm{O}$ trauma destrói certezas, abala verdades e altera nossa concepção espaço-temporal do mundo e de nós mesmos.

Segundo Cathy Caruth (1996, p. 4), é a própria natureza de "não-assimilação" do evento, ou seja, sua recusa em ser objeto de conhecimen- 
Aporia e Trauma na Crise de Significados do

to humano, que faz o trauma retornar para assombrar o indivíduo. Por essa razão, Edkins (2001) não se revela surpresa quando se depara com a incapacidade de testemunhas de eventos traumáticos em descrever o ocorrido, limitando-se a revivê-lo, como se presas a um fluxo de flashbacks contínuo. Há muito postulou Laplanche (1976, p. 406) que "é a memória do evento, e não o evento propriamente dito, que é traumático". No caso do Onze de Setembro, sobretudo por sua superexposição na mídia, os indivíduos puderam, literalmente, reviver a memória do trauma, sem abreviações ou condensações, quase que indefinidamente.

Edkins (2001) critica o papel das redes de televisão e da tecnologia, que basicamente reeditaram os eventos de $2001^{9}$ à exaustão, inscrevendo como permanentes e obrigatórias as emoções contraditórias provocadas pelo Onze de Setembro no imaginário coletivo americano. ${ }^{10}$ É dessa forma, inclusive, que o trauma se torna contagioso, pois até aqueles que não o viveram diretamente podem experimentá-lo e, de certo modo, sentir-se conectados à coletividade. Surge, então, uma ressignificação da própria identidade coletiva: "Só o verdadeiro nova-iorquino sabe o que foi aquele dia" ou "Você só é americano, se viveu o Onze de Setembro". Em certo sentido, o trauma funciona como fonte inesgotável para a construção discursiva da identidade nacional da coletividade.

Para Edkins (2001):

O evento traumático é aquele que abala nossas expectativas e preconceitos sobre como o mundo é. Nossos mapas mentais sobre o mundo deixam de funcionar. O trauma é um evento perante o qual antigas referências e linguagens ficam inertes. Em casos extremos, ele literalmente "desfaz" nosso mundo [...]. As categorias que cuidadosamente acumulamos para lidar com experiências diversas são destruídas por algo que as ultrapassa. Portanto, não experimenta- 
mos o trauma no momento [em que ele acontece]: nós o vemos, mas não o compreendemos. Os momentos traumáticos voltam, infinitamente, em pesadelos. [...] Não revivemos a violência propriamente dita, mas sim o momento de nossa sobrevivência. Precisamos então lidar com nossa própria surpresa de que ainda estamos vivos.

A noção de sobrevivência é fundamental no equacionamento da relação entre trauma e segurança. Para Gaddis (2004, p. 69), mais importante do que a queda das torres foi a queda do mito da inviolabilidade do território norte-americano. Com exceção de Pearl Harbor, os Estados Unidos não sofriam um ataque em solo nacional desde que as tropas inglesas atearam fogo à Casa Branca em 1814. Segundo ele, poucos eram os países que haviam se preocupado tão pouco, e por tanto tempo, com sua vulnerabilidade territorial. O Onze de Setembro derrubou uma das poucas grandes certezas que povoavam o imaginário nacional: o da invulnerabilidade territorial, ou o que Woodward (1960) chamou de "segurança gratuita". ${ }^{11}$ Considerando a crescente percepção de que a posição geográfica e o poder militar norte-americano tinham deixado de funcionar como garantia da segurança territorial, surge uma nova percepção de vulnerabilidade, que deve ser entendida à luz da queda do mito da segurança gratuita. A mudança cognitiva é assim descrita por Edkins (2002, p. 246):

Tornou-se claro que as certezas metafísicas tidas como naturais podiam ser destruídas. A segurança era uma ilusão: estávamos por demais vulneráveis. Bruscamente, as pessoas ficaram desorientadas e abaladas: as narrativas do tipo "preto no branco", as emoções definidas, as soluções fáceis que impulsionavam a cultura ocidental, tudo foi substituído por uma complexidade exaustiva que deixava as pessoas à deriva, onde rochas sólidas e seguras haviam cedido lugar a areias movediças, o familiar havia se 
Aporia e Trauma na Crise de Significados do Onze de Setembro

transformado em algo sinistramente desconhecido. Agora as sirenes soam diferentes, simultaneamente assustadoras e consoladoras. $\mathrm{O}$ trabalho parece irrelevante. A normalidade ainda está indefinida.

O trauma se insere na experiência do reconhecimento de nossa mortalidade. A vida somente se torna suportável se aderirmos a uma espécie de pacto não escrito, sobretudo na cultura ocidental, de esquecimento voluntário de nossa condição precária. O trauma lembranos, dolorosa e subitamente, que tal pacto é, na verdade, fútil e impossível. Somos mortais e vulneráveis, e a noção da segurança total não passa de um artifício ao qual recorremos para nos iludirmos de que podemos escapar da morte, o que nos dá alívio para a ansiedade que o reconhecimento de imortalidade nos causa.

A título ilustrativo, é interessante observar a relação entre a experiência do Onze de Setembro - tenha sido ela vivida diretamente, ou não - e a sensação de vulnerabilidade, de ansiedade e de incerteza que cresceu na sociedade norte-americana desde então. Desde 2001, especialistas ${ }^{12}$ tentaram mapear e avaliar a dimensão do trauma provocado pela incapacidade da psique humana em lidar com o trauma dos ataques terroristas. Em especial, psicólogos, terapeutas e profissionais da saúde chamam a atenção para o aumento, nas semanas e meses seguintes a setembro de 2001, de casos de depressão, de insônia, de ansiedade, de hiperatividade, de arritmia cardíaca, de pânico, entre outros sintomas que apontavam para um diagnóstico de transtorno por estresse pós-traumático relativo ao Onze de Setembro.

Eis o diagnóstico de Herscher e Pascual (2008, p. 1):

No dia seguinte ao colapso das torres do World Trade Center, Amanda Fuqua chegou ao trabalho no centro de São Francisco, a 3 mil milhas de distância. Sentou-se à mesa, tentou começar a trabalhar, mas surpreendeu-se com sua pró- 
pria descompostura. "As pessoas tentavam falar comigo e eu simplesmente desatava a chorar", explicou Fuqua. "Eu soluçava. Diziam para eu ir para casa, e foi bom ter feito isso. Não conseguia me concentrar em nada". Fuqua, uma consultora de recursos humanos de 22 anos, não perdeu nenhum ente querido nos ataques terroristas de Onze de Setembro contra o World Trade Center e o Pentágono. [...] Como Fuqua, os norte-americanos, vivam eles próximos ao epicentro ou a milhares de milhas de distância, ainda sofreram os efeitos do terrorismo nos dias, semanas e meses que se seguiram. Especialistas em trauma afirmam que um indivíduo pode ser severamente afetado por uma tragédia mesmo se não estava em uma situação de risco de vida e se não precisou procurar um ente querido desaparecido.

Os indivíduos estavam tendo uma reação normal a eventos profundamente anormais. O trauma, potencializado por uma constante evocação da memória do evento, seja pela televisão, seja pelos aparatos estatais, ou até mesmo na vida privada, ${ }^{13}$ pareceu ter sobrecarregado a capacidade da mente humana para lidar com emoções tão violentas e desgastantes. A nação sofria de estresse pós-traumático. "A América parece ter entrado em crise existencial", concluem.

Relacionar trauma e ansiedade existencial não é inédito. Sigmund Freud dedicou-se exaustivamente ao tema para compreender as causas e os sintomas que acompanham o estado de ansiedade. Em sua teoria da sedução, ${ }^{14}$ Freud (1963, p. 63) argumenta que "a ansiedade emergiu originalmente como reação a um estado de perigo", sendo então reexperimentada "sempre que uma situação semelhante ocorre". Por esse motivo, o trauma reside na memória, no contínuo lembrar da experiência original, e não no evento em si (LAPLANCHE; PONTALIS, 1973, p. 406). 
Aporia e Trauma na Crise de Significados do

Torna-se possível, assim, distinguir ansiedade de medo. Para Freud, a ansiedade (Angst) refere-se à angústia experimentada na expectativa de algo incerto, que não sabemos definir. É o estado emocional despertado pela memória de um evento traumático. A ansiedade possui uma qualidade de indefinição em relação a seu fim e objeto: ela existirá enquanto a memória traumática perdurar, independentemente do plano real. Já o medo (Furcht) ocorre quando o indivíduo encontra um objeto real sobre o qual pode projetar sua ansiedade.

Estudos tradicionais sobre transtornos por estresse pós-traumático ${ }^{15}$ localizam no medo a principal reação provocada pelo trauma. Consoante o chamado "paradigma do medo", indivíduos com vulnerabilidades biológicas, ou psicológicas, que vivem experiências-limite, passam a organizar suas vidas com base na crença de que nada na vida é certo, somente a morte. $\mathrm{O}$ fato de terem enfrentado uma situação em que suas próprias vidas estiveram em risco faz com que esses indivíduos reconheçam o sentido absurdo de uma existência em que tudo é imprevisível e incerto, exceto a morte. A ansiedade é provocada pela constatação de sua própria mortalidade e pelo medo quanto ao futuro. ${ }^{16}$

Em proposta que se alinha com nosso argumento, o psicanalista Janoff-Bulman (1992) defende o "paradigma das premissas de mundo", segundo o qual o trauma abala as três premissas fundamentais na vida dos indivíduos: o mundo é um lugar benevolente; a realidade tem sentido; e o "Outro" possui valor. Ao deslocar o foco do medo para a avaliação da realidade e do "Outro", o autor explora como esquemas e fatores cognitivos influenciam a reação dos indivíduos após um trauma. Sua observação de que os indivíduos seriam resistentes a mudanças que envolvam essas premissas de mundo nos faz reconhecer a razão pela qual uma mudança súbita pode ser traumática. Os indivíduos não conseguem conciliar o velho e o novo e, por isso, reagem pelo trauma. A ansiedade, nesse contexto, surge da dificuldade em aceitar e em se adaptar às mudanças. 
A proposta acima parece se encaixar no cenário do Onze de Setembro, no qual o conjunto de premissas que regia a sociedade norte-americana foi abruptamente abalado. Da noite para o dia, os indivíduos constatam que o mundo não é benevolente, que a realidade deixa de fazer sentido e - sobretudo após a perda de mais de 6 mil vidas - suas existências podem não ter mais valor. Para McFarlane e Van der Kolk (1996), a sociedade ressente-se da mudança súbita e tem dificuldade em domesticar o trauma, o que a leva a adotar narrativas de responsabilização para salientar o caráter não natural do novo esquema de realidade.

A terceira reação possível ao trauma, igualmente relevante para o Onze de Setembro, é o "paradigma da traição". Admitindo a utilidade social do não-reconhecimento da traição, Freyd $(1996,1999)$ sugere que a vítima de trauma causado por seu próprio provedor tenha que, mesmo que inconscientemente, permanecer na ignorância da traição. Para uma criança que tenha sofrido abuso do pai, por exemplo, o afastamento é impossível porque compromete sua própria sobrevivência. A ansiedade é gerada pelo sentimento de traição.

A mesma lógica é reproduzida por Shay (1994) em seu estudo sobre veteranos de guerra. $\mathrm{O}$ ambiente militar cria uma relação de "dependente-provedor", na qual os soldados passam a depender completamente dos aparatos militares para obter roupas, refeições, treinamento, remédios, equipamento, instruções etc. Assim, os combatentes, sobretudo após retornarem da guerra, sentem-se traídos pelo Estado por não terem recebido alimentação, roupas ou treinamento adequado, ou por terem deixado de receber o devido reconhecimento de seus esforços na volta para casa. ${ }^{17}$

De qualquer forma, os três paradigmas acima sugerem uma relação entre trauma, comunidade política e poder. No mundo moderno, tomamos como premissa a existência do Estado para assegurar ordem, estabilidade e segurança, ou seja, para evitar a ocorrência de novos 
Aporia e Trauma na Crise de Significados do

traumas, como se realmente tivesse existido um trauma original. ${ }^{18}$ Entretanto, a premissa acima está longe de ser pacífica. Basta lembrar a prerrogativa dos Estados em recrutar cidadãos para a guerra, o que os expõe ao risco. Determinadas políticas também podem ameaçar a segurança da população, como no caso de uma política externa agressiva. No nível doméstico, o Estado poderia usar da violência para punir desvios, como no caso das prisões.

Devemos reconhecer a estreita ligação entre o trauma, a comunidade política e o tipo específico de poder que se encontra em ação: o biopoder. Consoante o conceito de Foucault, o poder estatal no mundo moderno atua fazendo distinções, incluindo, ou excluindo, indivíduos do processo político, a ponto de retirar o valor da vida humana do processo político. Os indivíduos são reduzidos à massa, tornando-se objeto de vigilância, de controle, de disciplinamento e de punição. Por meio de normas arbitrárias, a biopolítica investe sobre a vida, excluindo e incluindo indivíduos e grupos, ajustando e domesticando seus corpos aos processos desejados pelo Estado. Assim, em nome dos que devem viver, decide-se quem deve morrer. Nas palavras de Foucault (2002, p. 305), é "a morte do outro, da raça ruim, que vai deixar a vida em geral mais sadia”.

Nesse sentido, Agamben (2004, p. 130-131) mostra como a biopolítica cria uma nova categoria de vida humana: a "vida nua", ou "esses corpos matáveis dos súditos que formam o novo corpo político do Ocidente". A base da democracia moderna, diz ele, deixou de ser o homem livre, "com suas prerrogativas e os seus estatutos"; agora é a vida nua, a vida "matável e insacrificável do homo sacer", vida que se pode deixar morrer, porque foi excluída da jurisdição humana. O trauma experimentado seria, então, a reação ao reconhecimento de nossa condição de vida nua. ${ }^{19}$

O trauma provocado pelo Onze de Setembro abalou as estruturas tradicionais que davam inteligibilidade à realidade e aos próprios indi- 
víduos. Abruptamente, a sociedade norte-americana perdeu seu entendimento sobre "a ordem das coisas". Em especial, ela perdeu o significado que tinha da própria América: o que era, qual o seu lugar no mundo, e quem eram os americanos nesse cenário de crise e de trauma? Não nos admira, portanto, que a indagação mais repetida na primeira hora tenha sido: Por que nos odeiam tanto? O fato é que o significado da identidade nacional americana é colocado em dúvida, sinalizando o início do colapso do discurso dominante de americanidade.

Os ataques do Onze de Setembro tiveram grande impacto no imaginário coletivo norte-americano. O pronto recurso a narrativas de "antes e depois" nos dias que se seguiram aos ataques, seja na mídia, seja nos canais oficiais do governo, sinaliza a forte tendência em transformar a data em marco de mudança histórica. Sua construção como momento de ruptura faz com que a data funcione como divisor de águas em termos políticos, sociais, culturais, econômicos e, sobretudo, cognitivos. Ao nosso ver, o Onze de Setembro deve ser interpretado como um momento de crise orgânica. Foi um momento de aporia, no qual significados foram deslocados de suas posições privilegiadas. De forma especial, as narrativas, mitos, símbolos e imagens que construíam discursivamente a identidade nacional americana deixaram de fazer sentido. Essas teriam sido as condições de possibilidade da "Guerra ao Terror": um discurso hegemônico articulado para eliminar a aporia, superar a crise e criar ordem.

\section{Notas}

1. Esta e as demais citações de originais em língua estrangeira foram livremente traduzidas para este artigo. 
Aporia e Trauma na Crise de Significados do Onze de Setembro

2. Kitty Coburn, em cobertura ao vivo do aeroporto de Nova Iorque. CNN, 11 de setembro de 2001, 10h40.

3. "É possível que a foto seja mais memorável que imagens em movimento porque ela constitui uma nítida fatia de tempo, e não um fluxo. A televisão é uma corrente de imagens subselecionadas, em que cada uma cancela a anterior. Cada foto é um momento privilegiado transformado em um fino objeto que pode ser guardado e revisto" (SONTAG, 1990, p. 17-18).

4. Como percebeu Zehfuss (2003, p. 513), se o Onze de Setembro ficou alojado em nossa memória, não foi em virtude da dimensão do ataque à superpotência em seu próprio território, mas sim porque foi um grande espetáculo. "Foi um evento trágico para os que perderam entes queridos. Mas, ao mesmo tempo, foi um espetáculo. O 'maior espetáculo de arte já visto', como disse o compositor Karlheinz Stockhausen de forma controversa, mas espontânea” (ZEHFUSS, 2003, p. 513).

5. Sturken (2002, p. 374) comenta que dar excepcionalidade a determinada data, no sentido de construir discursivamente um "antes" e um "depois", não tem nada de excepcional, pelo contrário. Lembrando outras declarações sobre datas de rupturas da História, ele alude a Virginia Woolf e Theodor Adorno: "Escrevendo em 1924 sobre a experiência da modernidade, Virginia Woolf declarou: 'em meados de dezembro de 1910, o caráter humano mudou'. Anos depois, Theodor Adorno escreveu que 'fazer poesia após Auschwitz era uma barbárie', indicando que a produção cultural havia sido irrevogavelmente mudada pelo Holocausto".

6. Sobre a tese do "fim da História", ver Fukuyama (1992). Para uma crítica, ver Perry Anderson (1992). Destacamos duas alusões a uma suposta relação entre a queda do muro de Berlim, os ataques terroristas de 2001 e a tese de fim da História. Michael Cox (2005, p. 132), ao comentar a década de 1990 do pósGuerra Fria, sugere que aquele foi um período no qual "a História simplesmente tirou férias". Tratava-se de um momento, segundo ele, de predomínio do pensamento que acreditava que a integração econômica e a expansão da democracia tornariam o mundo mais seguro. Em 2008 e, agora, sob os efeitos do Onze de Setembro, o filósofo Zizek (2008, p. 3) volta ao tema ao dizer que, simbolicamente, os ataques terroristas de 2001 representaram o fim da utopia de Fukuyama: "Foi o fim dessa era feliz [a da expansão do capitalismo liberal na década de 1990]. Voltou-se à História”.

7. A popularização da tese de Huntington, a ponto de elevar seu livro à categoria de best-seller no imediato pós-Onze de Setembro, evidencia a grande necessidade dos indivíduos de superar a aporia. 


\section{Erica Simone Almeida Resende}

8. Para um debate abrangente sobre cultura como sistema de significados, ver Schweder e Levine (1984).

9. Para Edkins (2001), o emprego da palavra "eventos" e da expressão “Onze de Setembro" continua a marcar o trauma. Segundo ela, expressões como "atrocidades", "ataques", ou "atos de guerra" sinalizam alguma tentativa de domesticação do trauma. Ainda hoje, deparar-se com o termo "eventos" é prova da sobrevivência do trauma.

10. Optamos por empregar o termo "americano" em contextos inseridos em práticas discursivas de construção do significado de "América". O uso de "americano", ao invés da forma "norte-americano", pretende marcar que estamos falando de uma "América" mítica, construída no plano simbólico-discursivo, ao contrário de "Estados Unidos”. Nesse sentido, ver Resende (2009).

11. Para Woodward (1960), os Estados Unidos haviam desfrutado de um grau excepcional de segurança militar física, não apenas eficiente e inconteste, mas sobretudo gratuita. A tese era de que, com dois oceanos e uma camada polar logo ao norte, o país havia recebido um verdadeiro presente da natureza, o que permitiu aos Estados Unidos promover uma segurança relativamente barata.

12. Ver Stanford... (2006), Large... (2006) e Terrorism... (2008).

13. Os autores indicam um novo assunto de conversa (social conversation topics): em vez de "Onde você estava no dia em que atiraram em Kennedy?", agora temos "Onde você estava no Onze de Setembro?".

14. A teoria da sedução trata das repercussões de uma realidade efetiva após o trauma, ou seja, quando um fato traumático do passado é interpretado à luz de um novo fato do presente capaz de se conectar à angústia original. De certo modo, trata-se de um passado que se insere no presente. Freud desenvolve seu argumento com base na noção da sedução, isto é, uma experiência sexual precoce que coloca uma criança em situação passiva a um avanço sexual de um adulto. Pela imaturidade, despreparo e falta de amadurecimento psicológico e físico, a criança não consegue interpretar e processar a experiência, o que provoca o trauma. O que é interessante observar na teoria de Freud, depois retomada por Laplanche, é o duplo aspecto temporal do trauma. Há o primeiro momento - o da experiência original -, no qual a lembrança não é patológica, nem traumatizante. E há o segundo momento, em que uma nova experiência no presente se associa à memória da experiência original. A lembrança da primeira experiência - ou sua memória - é que é traumática. Ver Laplanche (1976) e Laplanche e Pontalis (1973).

15. Ver também Herman (1992). Para sua aplicação em veteranos de guerra, ver Brett (1996). 
Aporia e Trauma na Crise de Significados do Onze de Setembro

16. De certa forma, encontramos eco da tradição da filosofia existencial no "paradigma do medo". Equiparando a noção de angústia ao conceito cristão de pecado, Kierkegaard (2001) entendia que todo indivíduo já nascia na angústia, pois seu "Eu" era um falso "Eu". Somente com a morte, ao reencontrar Deus, é que conheceria seu "Eu" verdadeiro. É possível identificar em sua obra alguns conceitos posteriormente retomados por Freud.

17. O caso de veteranos do Vietnã é exemplar deste paradigma, especialmente pelo sentimento geral de terem sido abandonados pelo Estado após a "derrota" e de não conseguirem se readaptar à vida civil.

18. É interessante a observação de Lozzano (2007) sobre a evocação de um "trauma coletivo originário" no estado de natureza hobbesiano na legitimação do estado de exceção.

19. Primo Levi (1987) mostra como o Holocausto marcou a fronteira onde o homem deixou de ser homem para ser a vida nua apontada por Agamben. Para Levi, nos campos de concentração, a vida era algo que podia ser usado instrumentalmente em experiências médicas, como trabalho escravo, ou como simples diversão. As punições eram arbitrárias e inquestionáveis. Não havia um "porquê" das coisas.

\section{Referências Bibliográficas}

AGAMBEN, G. Homo Sacer: o poder soberano e a vida nua I. Belo Horizonte: UFMG, 2004.

ANDERSON, P. O fim da história - de Hegel a Fukuyama. Rio de Janeiro: Jorge Zahar, 1992.

BLANCHOT, M. The writing of the disaster: "l'écriture du désastre". Lincoln: University of Nebraska Press, 1995.

BRETT, E. A. The classifications of posttraumatic stress disorder. In: VAN DER KOLK, B. A.; MCFARLANE, A. C.; WEISAETH, L. (Ed.). Traumatic 


\section{Erica Simone Almeida Resende}

stress: the effects of overwhelming experience on mind, body, and society. New York: Guilford Press, 1996. p. 117-128.

CAMPBELL, D. Imagining the real, struggling for meaning. InfoInterventions, 6 Oct. 2001.

Time is broken: the return of the past in the response to September 11. Theory \& Event, v. 5, n. 4, 2002.

CAREY, P. Letter to The Observer. The Observer, London, 23 Sept. 2001.

CARUTH, C. Unclaimed experience: trauma, narrative, and history. Baltimore: John Hopkins University Press, 1996.

COX, M. From the Cold War to the War on Terror. In: BAYLIS, J.; SMITH, S. (Ed.). The globalization of world politics. 3. ed. Oxford: Oxford University Press, 2005. p. 131-157.

DER DERIAN, J. In terrorem: before and after 9/11. In: BOOTH, K.; DUNNE, T. (Ed.) Worlds in collision: terror and the future of global order. New York: Palgrave McMillan, 2002a. p. 101-117.

—. The war of networks. Theory \& Event, v. 5, n. 4, 2002 b.

9/11: before, after, and in between. In: CALHOUN, C.; PRICE, P; TIMMER, A. Understanding September 11. New York: New Press, 2002c. p. 177-190.

EDKINS, J. The absence of meaning: trauma and the events of 11 September. InfoInterventions, 5 Oct. 2001.

. Forget trauma? Responses to September 11. International Relations, v. 16, n. 2, p. 243-256, 2002.

FOUCAULT, M. Em defesa da sociedade. São Paulo: Martins Fontes, 2002.

FREUD, S. Therapy and technique. New York: Collier, 1963.

FREYD, J. J. Betrayal trauma: the logic of forgetting childhood abuse. Cambridge: Cambridge University Press, 1996.

Blind to betrayal: new perspectives on memory for trauma. The Harvard Mental Letter, v. 15, n. 12, p. 4-6, 1999. 
Aporia e Trauma na Crise de Significados do

Onze de Setembro

FUKUYAMA, F. O fim da história e o último homem. Rio de Janeiro: Rocco, 1992.

GADDIS, J. L. Surprise, security, and the American experience. Cambridge: Harvard University Press, 2004.

GEERTZ, C. The interpretation of cultures. New York: Basic Books, 1973.

GÖLE, N. Close encounters: Islam, modernity, and violence. In: CALHOUN, C.; PRICE, P; TIMMER, A. Understanding September 11. New York: New Press, 2002. p. 332-344.

HERMAN, J. L. Trauma and recovery. New York: Basic Books, 1992.

HERR, M. Dispatches. New York: Avon Books, 1991.

HERSCHER, E.; PASCUAL, P. Special report: coping with the trauma of 9/11. Consumer Health Interactive, 26 Feb. 2008.

HUNTINGTON, S. P. The clash of civilizations and the remaking of world order. New York: Simon and Schuster, 1996.

JANOFF-BULMAN, R. Shattered assumptions: towards a new psychology of trauma. New York: The Free Press, 1992.

KAUFMAN, E. Falling from the sky. Diacritics, v. 28, n. 4, p. 44-53, Winter 1999.

KIERKEGAARD, S. O desespero humano. São Paulo: Martin Claret, 2001.

KNAPP. C. Consciousness on overload. Salon.com, 20 Sept. 2001.

LAPLANCHE, J. Life and death in psychoanalysis. Baltimore: Johns Hopkins University Press, 1976.

; PONTALIS, J. B. The language of psychoanalysis. New York: W. W. Norton, 1973.

LARGE study of World Trade Center responders finds persistent health problems in many. ScienceDaily, 6 set. 2006. Disponível em: <http://www.sciencedaily.com/releases/2006/09/060906084107.htm>. Acesso em: 14 abr. 2009.

LEVI, P. If this is a man. London: Abacus, 1987. 


\section{Erica Simone Almeida Resende}

LINDE, C. Life stories: the creation of coherence. Oxford: Oxford University Press, 1993.

LOZZANO, B. J. Sovereign in the state: an essay on trauma and the decision of the war on terror. 2007. 245 f. Tese (Doutorado em Ciência Política) - University of California, Santa Cruz, EUA.

MCFARLANE, A. C.; VAN DER KOLK, B. A. Trauma and its challenge to society. In: VAN DER KOLK, B. A.; MCFARLANE, A. C.; WEISAETH, L. (Ed.). Traumatic stress: the effects of overwhelming experience on mind, body, and society. New York: Guilford Press, 1996. p. 24-45.

PASSAVANT, P. A.; DEAN, J. Representation and the event. Theory \& Event, v. 5, n. 2, 2002.

RAYNER, T. Time and the event: reflections on September 11, 2001. Theory $\boldsymbol{\&}$ Event, v. 5, n. 4, 2002.

RESENDE, E. S. A. Americanidade, puritanismo e política externa: a (re)produção da ideologia puritana e a construção da identidade nacional nas práticas discursivas da política externa norte-americana. 322 f. Tese (Doutorado em Ciência Política) - Faculdade de Letras, Filosofia e Ciências Humanas da Universidade de São Paulo, São Paulo, 2009.

ROSS, M. H. The political psychology of competing narratives: September 11 and beyond. In: CALHOUN, C.; PRICE, P; TIMMER, A. Understanding September 11. New York: New Press, 2002. p. 303-320.

SCHWEDER, R. A.; LEVINE, R. A. (Ed.). Culture theory: essays on mind, self, and emotion. Cambridge: Cambridge University Press, 1984.

SHAY, J. Achilles in Vietnam: combat trauma and the undoing of character. New York: Touchstone Books, 1994.

SONTAG, S. On photography. New York: Anchor Books, 1990.

STANFORD psychiatrist on 9/11 and post-traumatic stress disorder. Stanford News, 9 mai. 2006. Disponível em: <http://mednews.stanford.edu/releases/2006/september/5q-spiegel.html>. Acesso em: 14 abr. 2009.

STURKEN. M. Memorializing absence. In: CALHOUN, C.; PRICE, P; TIMMER, A. Understanding September 11. New York: New Press, 2002. p. 374-384. 
Aporia e Trauma na Crise de Significados do Onze de Setembro

TALBOT, S.; CHANDA, N. (Org.). A era do terror. O mundo depois de 11 de setembro. Reflexões e alertas para o futuro. Rio de Janeiro: Campus, 2002.

TERRORISM, acute stress, and cardiovascular health. Archives of General Psychiatry, v. 65, n. 1, jan. 2008. Disponível em: <http://archpsyc.ama-assn. org/cgi/content/short/65/1/73>. Acesso em: 14 abr. 2009.

WOODWARD, C. V. The age of reinterpretation. American Historical Review, v. 66, n. 1, p. 1-19, Oct. 1960.

ZEHFUSS, M. Forget September 11. Third World Quarterly, v. 24, n. 3, p. 513-528, 2003.

ZIZEK, S. Os limites do sistema estão ficando claros. O Globo, Rio de Janeiro, $1^{\circ}$ nov. 2008. Prosa \& Verso, p. 3.

\section{Resumo}

\section{Aporia e Trauma na Crise de Significados do Onze de Setembro}

Recorrendo a conceitos e a teorias que relacionam significados, representações, memória e trauma, destacaremos como os acontecimentos de Onze de Setembro foram capazes de desestabilizar representações e significados, quebrar a linha da História, subverter sentidos, romper percepções espaço-temporais e abalar as grades de inteligibilidade que permitiam que os americanos dessem sentido à realidade e a si próprios. Nosso objetivo é compreender como representações mudas e hiper-reais dos eventos de 2001 provocaram uma situação de falha de linguagem, o que teria resultado em um momento de aporia. Arguiremos que o Onze de Setembro, devido à dificuldade de significação, encontrar-se-ia no cerne de um trauma nos imaginários coletivos americanos.

Palavras-chave: Estados Unidos - Onze de Setembro - Representações - Significação - Trauma 


\section{Abstract}

\section{Aporia and Trauma in the Crisis of Meanings of 9/11}

Employing concepts and theories that relate meanings, representations, memory and trauma, we attempt to show how the 9/11 events have been able to disstabilize representations and meanings, break the line of History, subvert senses, bend space-time perceptions, and shake the grids of intelligibility that had allowed Americans to make sense of reality and of themselves. Our aim is to understand how mute and hiperreal representations of the events of 2001 provoked a situation where language failed, producing a moment of aporia. We will then argue that $11 / 9$, due the difficulty of its signification, sits at the heart of a trauma in the American collective imaginaries.

Keywords: United States - 9/11 - Representations - Signification Trauma 